Revista Bioética

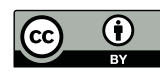

Print version ISSN 1983-8042 On-line version ISSN 1983-8034

Rev. Bioét. vol.28 no.4 Brasília Out./Dez. 2020

Doi: 10.1590/1983-80422020284424

\title{
ATUALIZAÇÃO \\ Sobre a desfiguração do conceito de humano na bioética
}

João Cardoso de Castro ${ }^{1}$, Murilo Cardoso de Castro ${ }^{2}$

1. Grupo de Pesquisa Ética e Bioética, Centro Universitário Serra dos Órgãos, Teresópolis/RJ, Brasil. 2. Universidade Federal do Rio de Janeiro, Rio de Janeiro/RJ, Brasil.

\section{Resumo}

Este ensaio apresenta a interpretação hegemônica de "humano" na bioética e representa esse paradigma a partir do conceito de Dasein (ser-aí), de Martin Heidegger. A primeira parte do artigo discute de que maneira o "esquecimento do ser" (Seinsvergessenheit) possibilita emergir o "sujeito", que encontra na razão e na metafísica modernas solo fértil para o predomínio do modelo dual, sujeito-objeto, em todos os fenômenos, e em específico na bioética. Buscando outro encaminhamento, na parte final do trabalho reflete-se acerca da originalidade da interpretação heideggeriana sobre a experiência humana enquanto Dasein. Pretende-se potencializar debate que possa alargar o horizonte da bioética ao desencobrir o conceito de "humano" e, com ele, toda uma gama de conceitos herdeiros", integralmente submersos em camadas calcificadas de tradição.

Palavras-chave: Bioética. Humanos. Filosofia. Metafísica.

\section{Resumen}

\section{Sobre la desfiguración del concepto de humano en la bioética}

Este ensayo presenta la interpretación hegemónica del concepto de "humano" en la bioética y representa este paradigma con base en el concepto de Dasein (ser-ahí), de Martin Heidegger. En la primera parte del artículo, se discute la manera en que el "olvido del ser" (Seinsvergessenheit) permite que surja el "sujeto", que encuentra en la razón y en la metafísica modernas un terreno fértil para el predominio del modelo dual, sujeto-objeto, en todos los fenómenos y, en concreto, en la bioética. Buscando otra dirección, en la parte final del trabajo, se reflexiona sobre la originalidad de la interpretación heideggeriana de la experiencia humana en cuanto Dasein. Se pretende potenciar un debate que pueda ampliar el horizonte de la bioética al desvelar el concepto de "humano" y, con él, toda una gama de conceptos "herederos", completamente sumergidos en capas calcificadas de tradición.

Palabras clave: Bioética. Humanos. Filosofía. Metafisica.

\section{Abstract \\ On the distortion of the concept of human in bioethics}

This article presents the hegemonic interpretation on the concept of "human" in Bioethics and represents this paradigm from Martin Heidegger's concept of Dasein ("there being"). In the first part, we discuss how the "oblivion of being" (Seinsvergessenheit) allows the emergence of the "subject," who finds in modern reason and metaphysics fertile ground for dominance of the dual model, subject-object, on all contemporary phenomena, specifically bioethics. In the final part of the article, we reflect on the originality of Heidegger's interpretation of human experience as Dasein. We intend to broaden the debate and the bioethical perspective on the concept of "human" and, with it, a whole range of "successors" concepts completely submerged in layers of tradition. Keywords: Bioethics. Humans. Philosophy. Metaphysics. 
Para Martin Heidegger, metafísica tem sentido por vezes pejorativo, cujo significado só se torna claro no contexto de toda sua filosofia. A metafisica funda uma era, nos princípios que sustenta sob todos os fenômenos que distinguem esta era ${ }^{1}$. Este fundamento metafísico apoia-se em dois pilares, nem sempre explícitos: determinada interpretação do ente e determinada concepção da verdade. Ou seja, na base fundacional da "metafísica da modernidade", sobre a qual se elabora todo o pensamento acerca dos fenômenos contemporâneos relevantes - a exemplo da ciência e da técnica -, briIha intensamente uma determinação do ser do ente, a representação, e configura-se um conceito de verdade, a certeza do enunciado da representação.

Como fenômeno relevante da modernidade, há na bioética determinada interpretação do ente, em particular do "ser" humano, e determinado entendimento do que seja a essência da verdade, na certeza da representação do "modelo" de ser humano. A bioética tem sua origem em considerações pertinentes sobre o avanço das chamadas biotecnologias, e em consonância com a ética moderna, elaborada em termos de uma ética "prática" ou "aplicada" fundamentada e constituída pela metafísica da modernidade.

Os entes a que se refere essa ética prática, e mais especificamente a bioética, são dados e fixados por uma interpretação da razão moderna sobre o que é "ser humano", "sujeito", "objeto", "outro" etc. Do mesmo modo, uma concepção de verdade, de fidelidade e de sentido fundamenta determinada representação de ser humano e, consequentemente, de valor e excelência. E muito já se refletiu sobre o modo como esses pressupostos da razão moderna alicerçam o pensamento ético.

Este trabalho parte da constatação de que vivemos uma "crise ética". No entanto, para além da compreensão do termo como colapso de valores que outrora regiam a experiência humana, entendemos que um horizonte muito antigo está na origem dessa "crise": a separação entre o que originariamente se compreendia como "ser humano" - e não unicamente "ser vivente" - e o que se compreende como "humano", apenas, desde o humanismo renascentista e do cogito cartesiano.

Como motor dessa crise e se movimentando com cada vez mais vigor dentro dela há o que Heidegger denominou "esquecimento do ser" (Seinsvergessenheit) e "abandono do ser" (Seinsverlassenheit), sobretudo pela restrição consagrada na interpretação moderna que reduz a expressão "ser humano" apenas a "humano". Essa interpretação estilhaçada do "humano", incapaz de dizer o ser do humano em sua profundidade radical, encontra-se implicada - ou poderíamos dizer "aplicada" - em uma ética moderna que fica aquém daquela concebida em sua referência ao ethos, desde o pensamento originário até Aristóteles. Daí a proliferação de comitês de ética e de normativas de toda natureza, em face da impotência da consagrada representação de ser humano, que repercute sobre a própria bioética.

Mais do que nunca, cabe o convite a questionar os "pilares fundadores" da metafísica moderna "interpretação do ente" e "essência da verdade" enquanto balizadores da razão moderna, orientando o pensamento que navega pelas águas turbulentas da ciência e da técnica contemporânea, para citar apenas alguns de seus desdobramentos. Este trabaIho foca em refletir sobre aspectos da interpretação estilhaçada de ser humano - o "ente" ou o "sendo" que todos somos - conforme hegemonicamente concebido no campo da bioética. Na esteira deste objetivo - qual seja, demonstrar equívocos na interpretação do "ser" humano como apenas "humano" -, pretende-se aportar elementos para uma nova interpretação do "humano" a partir do conceito de Dasein (ser-aí) na filosofia de Martin Heidegger.

A fim de evidenciar os pressupostos questionáveis desse pilar da bioética, procura-se empreender o que Heidegger denomina "meditação": coragem para tornar no que é mais questionável (Fragwürdigste) a verdade dos pressupostos próprios e o espaço dos objetivos próprios ${ }^{1}$. O leitor é convidado, portanto, a meditar sobre a expressão mais completa de nossa realidade: "ser humano". Mas cabe aqui um alerta importante: não se deve confundir meditação com paralisia e contemplação passiva. O pensar meditativo não se confunde com a mera maquinação humana; ele está para além da reflexão instrumentalizada.

E isso só é possível pois, mesmo que a perspectiva de "ser" humano contaminada pela tecnociência seja hoje dominante, ainda há possibilidade de um reconhecimento, de um chamado da consciência, de um apelo do ethos. Uma lembrança da morada do "ser" humano que, ao se colocar à escuta de tal chamada, de tal apelo (Ruf), torna tudo "re-versível", no sentido de retornável ao centro, à morada do homem, ao ethos, de onde pode brilhar a verdadeira ética de que tanto carecemos.

\section{A miséria sujeito-objeto}

A "razão" (significando tanto o grego noûs, inteligência, quanto logos, linguagem), a partir 
de seu pseudofundamento em um sujeito pensante, falante e agente, adquire sua credencial de "moderna" e doravante rege todas as relações humanas, seja de um humano consigo mesmo, seja com outros humanos ou com as coisas. Tudo agora é regulado sob a égide do "humano", afastado do que para Heidegger seria sua "morada": o ethos.

McNeill explica que o ethos deve ser compreendido temporalmente, como um modo de ser, em termos de nossa postura e conduta no momento da ação - na maneira pela qual somos mantidos e nos mantemos e, assim, "permanecemos" na presença (Dasein) ${ }^{2}$. No "abandono do ser" (Seinsverlassenheit), expressão utilizada por Heidegger para se referir à omissão da reflexão sobre o "ser" (Sein) na filosofia ocidental, vige o que se denominará "relação sujeito-objeto". Esta disposição não foi somente grande impulso para a ciência moderna, emergente à mesma época, mas um divisor de águas para o ser humano, doravante considerado apenas em seu aspecto "humano, demasiado humano", com sede no corpo, onde se assenta uma "mente", e de onde, enquanto "sujeito", é capaz de pensar, falar e agir, sempre em relação a objetos, ou seja, ao mundo e aos entes intramundanos:

O advento do sujeito não resulta, para Heidegger, de uma mutação da essência do homem como animal racional, mas de uma mutação da essência da verdade. $O$ homem não decide um belo dia se tornar sujeito. Buscando o subjectum, quer dizer, a coisa que "sustenta" suas próprias qualidades (a palavra "sujeito" quer dizer "suporte"), o subjectum mais estável, sólido, o mais constantemente presente, mas sobretudo o mais verdadeiro, o mais certo, Descartes o situa não no homem (sempre considerado como um composto), mas no eu, alma, razão, pensar - termos equivalentes. É a verdade definida a partir da certeza para a consciência (e não mais a partir do eidos, da energeia ou actualitas) que exige um "sujeito" no qual a adequação da evidência se faça na presença a si sem falha do instante ${ }^{3}$.

Pelo fio condutor da metafísica da modernidade, a "representação", é possível desconstruir ainda mais o "sujeito", como o faz $\mathrm{Haar}^{3}$ ao recorrer ao ensaio de Heidegger ${ }^{4}$ e elaborar devidamente este traço singular da razão moderna: a representação é objetivação investigante e dominante. Ou seja, a representação é uma prática investigativa com o propósito de "conquistar" o ente por inteiro por meio do pensamento que calcula de um "sujeito".
O termo re-presentação, no sentido crítico que lhe é dado, pertence a uma interpretação, ou melhor, a um impensado da essência do sujeito, pois nem Descartes, nem Kant, tampouco Hegel e Nietzsche definem explicitamente o sujeito pela representação. O que está implicado na representação é, em primeiro lugar, a objetivação ilimitada de todo ente, que compreende necessariamente a auto-objetivação do sujeito. Esta é a "cena" sobre a qual todo ente, aí compreendido ele mesmo, deve aparecer para ser conhecido e confirmado em sua certeza. Pensar, enquanto re-presentar, é postular o ente em totalidade como oposto (Gegenstand), mas também é se presentar a si mesmo como sujeito objetivado, diante de si mesmo. Em segundo lugar, esta dupla apresentação comporta a necessidade de se submeter à verdade como certeza, isto é, à garantia de um cálculo. A representação é método calculante que assegura a apreensão sobre a presença constante, sem descanso, disto que é calculável. O método calculante implica uma agressão, um "ataque" contra o ente em sua totalidade ${ }^{5}$.

Logo, é precisamente neste sentido, desde a necessidade de efetuar um assalto técnico sobre o que é dado, que vimos emergir o conceito de sujeito. A "subjetividade", limitada, se dá pela separação fantasiosa entre sujeito e objeto, na qual um objeto qualquer se apresenta como projeção do sujeito. A "entidade", isto é, tudo que se apresenta, tem agora o sentido de "re-presentidade" do sujeito que a representa.

Não se trata de dizer que o ente, qualquer que seja, é mera representação ou ocorrência na consciência humana. Também não se pretende duvidar da realidade do ente enquanto algo que é constatado em si e a partir de si em seu sendo ${ }^{5}$. No entanto, cabe refletir sobre quais são as implicações da interpretação de ente que vigora na modernidade, sobre o que significa, nesse caso, "ser", e como o ente precisa ser alcançado e assegurado pelo homem enquanto aquele que se tornou sujeito. Esta longa passagem de Heidegger joga luz sobre essas questões:

Ser é a re-presentidade assegurada na re-presentação calculadora, uma re-presentidade por meio da qual são assegurados por toda parte para o homem o seu modo de proceder em meio ao ente, o escrutínio do ente, a conquista, o assenhoreamento e a colocação do ente à disposição; isso de tal forma que ele mesmo pode ser por si mestre de seu próprio asseguramento e de sua própria segurança. (...) Um traço fundamental de toda determinação metafísica essencial da verdade expressa-se na 
sentença que concebe a verdade como concordância do conhecimento com o ente: veritas est adaequatio intellectus et rei [a verdade é adequação entre $o$ intelecto e a coisa]. Segundo aquilo que foi dito anteriormente, porém, vemos agora claramente que essa "definição" usual da verdade sempre se transforma de acordo com o modo de ser do ente com o qual o conhecimento deve concordar, assim como de acordo com o modo como é concebido o conhecimento, que deve se encontrar em concordância com o ente. $O$ conhecer enquanto percipere $e$ cogitare no sentido de Descartes possui a sua distinção no fato de ele só admitir como conhecimento aquilo que é a-presentado como indubitável ao sujeito por meio do representar e que é calculável a todo momento uma vez mais como algo assim posicionado. Mesmo para Descartes, o conhecimento se orienta pelo ente. Nesse caso, porém, só é válido como ente aquilo que é assegurado sob a forma da re-presentação e da auto-a-apresentação caracterizadas. Um ente não é senão aquilo de que o sujeito pode estar seguro no sentido de sua representação. $O$ verdadeiro é apenas o assegurado, o certo. Verdade é certeza, e para essa certeza permanece decisivo o fato de nela o homem estar a cada vez certo e seguro de si mesmo. Por isso, para o asseguramento da verdade enquanto certeza em um sentido essencial, o pro-cedimento e o asseguramento-de-antemão são necessários. O "método" obtém agora um peso metafísico que está por assim dizer atrelado à essência da subjetividade ${ }^{6}$.

Nesse sentido, a representação assegura ao sujeito a possibilidade de uma ciência. A representação que se processa sobre o real, assegurando e garantindo seu status, é a elaboração que processa o real e o ex-põe numa objetidade. Com isso, todo real se transforma, já de antemão, numa variedade de objetos para o asseguramento processador das pesquisas científicas e, por que não, do modo de ser e agir do humano. A primazia da certeza científica anda pari passu com a valorização do "sujeito", que opera e realiza os feitos notáveis da ciência e do pensamento técnico.

Esse "enquadramento" do humano enquanto "sujeito" servia ao projeto iluminista de "intelectualizar" a natureza, por meio da catalogação sistemática de toda a sua diversidade e da representação fidedigna e matemática de sua forma figurativa. Emerge, com intensidade constante e gradativa, a figura de um "sujeito racional", único capaz de poder apreender o "todo", atribuindo-Ihe uma "ordem", uma "ordenação" racional. Este mesmo paradigma foi apropriado pelas éticas modernas, configurando a maneira como se discute a ação e, por conseguinte, os conceitos de "autoria", de responsabilidade.

Mas em quais condições vimos emergir o paradigma do "sujeito"? Há diversas respostas possíveis para essa questão. No entanto, entendemos que um motivo se destaca: o afã de desconstruir os valores medievais. Assim, a partir do Renascimento, vimos se esvaziar e perder encanto o paradigma que até então norteara o modo de ser do homem ocidental, fundado sobretudo nas concepções do teísmo e do criacionismo, ou seja, na crença em deuses e na criação do mundo desde a vontade de um ente sobrenatural. Esse período da história europeia, do século XIV ao XVII, considerado a ponte cultural entre a Idade Média e a Modernidade, marca de maneira fundamental o nascimento do "sujeito".

Muitos autores dissertaram com imensa desenvoltura sobre esse declínio da metafísica medieval, mas poucos com o talento de Friedrich Nietzsche 7,8 . Para ele, o nascimento do sujeito marca também a morte de Deus: Deus morreu! Nós o matamos... ${ }^{9}$, diz o filósofo alemão. Desmantelamos os paradigmas que orientavam nossos valores. Na primeira parte de Assim falou Zaratustra, Nietzsche ${ }^{8}$ relata três transformações do espírito, que são anunciadas pelo próprio Zaratustra. $\mathrm{O}$ anúncio consiste em mostrar como o espírito se torna camelo; o camelo, leão; e o leão, por fim, criança. Para compreender o salto em relação aos paradigmas de outros tempos, nos interessa particularmente o modo de ser do leão e do camelo. Segundo Cabral:

No que tange à questão ético-axiológica, o camelo é aquele modo de ser que, a exemplo do que ocorreu na Idade Média, assume a força do "Tu deves" (...). "Tu deves" é a expressão que assinala a submissão irrestrita da existência aos cânones morais-axiológicos positivados ou objetivados pela tradição greco-cristã que há muito norteia todo [o] Ocidente. (...) Antes de a situação aparecer, já se sabia, de antemão, o que se deveria fazer. A sexualidade, a vida política, a vida econômica etc. já eram guiadas pelas "rédeas" da moral cristã positivada em forma de manual doutrinário, que serviu de a priori deontológico do homem medieval ${ }^{10}$.

O texto nietzschiano anuncia uma transmutação: o camelo se transforma em leão repentinamente, pois fomos tomados por outro modo de ser. Isto é, em lugar do "tu deves", surge o "eu quero". Finalmente conquistamos nossa liberdade, precisamente porque não estamos mais à mercê do "tu deves". Como aponta Cabral: 
Não se diz mais: "sigo o que disseram que devo"; mas: "devo seguir justamente o que quero". É a partir disto que é o Eu que, agora, no vigor do modo de ser do leão, o agir é confeccionado, efetivado. O Eu é o próprio legislador e plasmador de toda realidade ético-axiológica. (...) É fácil notar o paralelo existente entre a tipologia mencionada - camelo, leão - e o desdobramento da destinação do pensamento ocidental. Isto porque, como já foi dito, tal tipologia também diz respeito à presença de um horizonte de sentido desde o qual a totalidade dos modos de ser do ente que somos cresce e se intensifica, ou seja, vigora inclusive o pensamento filosófico. Neste sentido, o camelo refere-se ao pensamento grego, pós-socrático, principalmente aquele desenvolvido nas escolas - e ao pensamento medieval-patrístico e escolástico. Já o leão diz respeito a todo pensamento moderno, isto é, pós-cartesiano ${ }^{11}$.

Em lugar da aquiescência diante do que "é", ou de diretrizes divinas que guiem a ação, temos agora "nós mesmos", estruturas corpóreas dotadas de uma razão capaz de agir, pensar e deliberar sobre a realidade. Vigora desde então um domínio absoluto do elemento subjetivo que doravante conduz toda a humanidade e toda a sua compreensão de mundo. Segundo Heidegger ${ }^{12}$, é na esteira da filosofia cartesiana que se manifesta com clareza esta metafísica do ente "homem" enquanto "sujeito".

Antes de Descartes, e ainda com ele, todo ente é concebido como sub-iectum. 0 termo sub-iectum é a tradução e interpretação latinizada do termo grego hypokeimenon, que significa aquilo que subjaz, aquilo que se encontra na base, aquilo que por si mesmo já se encontra aí defronte. Segundo Heidegger ${ }^{12}$, por meio de Descartes e desde então o homem, o "eu" humano, se torna predominantemente "sujeito". E na medida em que essa interpretação separa a experiência humana em corpo e mente (res extensa e res cogitans), ele, humano, passa a fornecer a medida para a entidade de todo e qualquer ente.

O próprio termo "razão" é oriundo do latim ratio, "medida". Neste sentido, a profundidade originária do conceito de logos se vê reduzida a uma instância do humano, capaz de conceber como "real" somente aquilo que pode ser calculado, medido, mensurado. Isso significa que junto ao humano enquanto sub-iectum encontra-se agora uma decisão quanto àquilo que pode ser efetivamente estabelecido como "sendo".

O próprio homem é aquele para o qual essa disposição se acha reconhecidamente como tarefa. O sujeito mostra-se como "subjetivo" pelo fato e no fato de a determinação do ente e, com isso, a determinação do próprio homem não serem mais restritas a nenhum limite, mas terem em todos os aspectos os seus limites suprimidos. A relação com o ente é o pro-cedimento de assenhoreamento em meio à conquista e ao domínio do mundo. $O$ homem entrega ao ente a medida, porquanto determina a partir de si e em direção a si mesmo aquilo que pode ser considerado como sendo. O padrão de medida é a presunção da medida, uma presunção por meio da qual o homem é fundado enquanto subiectum, como o ponto central do ente na totalidade. Todavia, é preciso certamente considerar o seguinte: o homem não é aqui um eu egoísta isolado, mas "sujeito", o que significa dizer que ele se coloca a caminho de um descerramento calculador e representador ilimitado do ente ${ }^{13}$.

Diante da emergência cada vez mais radical do sujeito, o pensamento que calcula (das rechnende Denken) ${ }^{14}$ encontra seu vértice na metafísica da modernidade, ou metafísica da representação. Resta agora buscar valor e sentido em nossa vida infinitamente diminuta, diante deste todo incomensurável, impossivel de reconhecer-nos como parte ou qualquer participação ${ }^{15}$. Seu desdobramento mais radical é o predomínio do pensamento técnico sobre todas as disciplinas de conhecimento, aí incluída a ética e, por conseguinte, a bioética. E esse é o motivo pelo qual a crise ética contemporânea se instala como "crise subjetiva", ou "crise da racionalidade".

Impõe-se o sujeito cartesiano, do conhecimento, e por conseguinte uma série de conceitos "herdeiros", como o agir, o decidir, o deliberar. Todas essas instâncias são agora abduzidas pelo calcular. Segundo Heidegger, para a razão moderna, e portanto para o homem-sujeito, o surgimento de um grão, por exemplo, é um processo químico inserido no conjunto das forças e das unidades componentes de uma causalidade recíproca, mecanicamente entendida, entre a coisa semente, as propriedades do solo e a irradiação do calor ${ }^{16}$.

Esse sistema de interpretação do real vigora no interior da própria bioética. Assim, a representação moderna só consegue ver um sistema mecânico de causa e efeito entre processos, que tem por consequência determinados resultados. Regidas pela razão moderna, as éticas contemporâneas são e permanecerão "mecânicas". Mas qual é a contribuição do Dasein heideggeriano para esse imbróglio? De que maneira uma nova interpretação do humano pode oferecer um novo início para a bioética? Essas são as perguntas que orientam a próxima seção. 


\section{Ser humano enquanto Dasein}

De tudo que foi dito até aqui, fica clara certa interpretação de "humano" como um composto, a saber: um corpo (que os gregos chamavam de soma) e a razão. Portanto, segundo a tradição, o "homem" é o vivente capaz de raciocinar, possuidor do logos, o animal racional. E a razão, aqui compreendida à luz da modernidade, é o poder de perceber, de captar, juntar, compactar, reunir, sintetizar (...). E isso, diz-se, é um poder, uma força interna ${ }^{17}$.

Tal suposição leva a interpretar o humano como composto de um dentro e um fora, um interno e um externo. Mas seria possível pensar o humano não mais no contexto dessa estrutura (dentro versus fora, sujeito versus objeto)? E, ainda, por que deveríamos nos opor a essa perspectiva predominante? A resposta à primeira questão é sim, mas acreditamos que seja mais profícuo focar a segunda pergunta. É preciso dar um salto que nos possibilite abandonar o paradigma dual que impede a compreensão integral do fenômeno.

Como nos alerta Fogel, é preciso desimaginar que o homem seja, p. ex., um eu, ou uma consciência, ou uma alma, ou um espírito. Ao contrário, é igualmente necessário desaprender ou desimaginar que o homem seja, de cara, algo como matéria, energia, corpo físico, ou biofisiológico, base de impulsos, instintos, reflexos ou algo assim natural. O homem, a vida, ou a existência humana (assim é entendido aqui o homem), de cara, é coisa nenhuma, algo nenhum, mas... Mas o quê? Um vazio, um oco, um buraco, que pode se denominar possibilidade da possibilidade. Melhor e mais precisamente: a realidade da liberdade como possibilidade da possibilidade ${ }^{18}$.

Além da contribuição do pensamento grego, a concepção de homem como realidade da liberdade como possibilidade da possibilidade, pronunciada originalmente por Kierkegaard ${ }^{19}$, foi, segundo Fogel, uma das grandes influências para Heidegger pensar o humano não mais como algo já dado, feito ou constituído, quer dizer, já fixado, seja como eu, ou como uma alma, ou como um indivíduo, ou como consciência (...) ou um sujeito ${ }^{20}$. Mas o que é, afinal, o humano?

Para se referir ao homem, Heidegger utiliza o termo Dasein. Três considerações de caráter preliminar aqui se fazem pertinentes: 1) o termo é considerado por Heidegger intraduzível; 2) o Dasein não é uma resposta à pergunta "o que é o homem?"; e 3) o projeto analítico heideggeriano, colocado em curso em Ser e tempo ${ }^{21}$, sua obra mais importante, busca compreender a questão do sentido do ser (Frage nach dem Sinn von Sein) e, portanto, jamais teve como finalidade última compreender especificamente o ser-aí, mas dele se valer para responder a esta questão.

Sobre a primeira colocação, é preciso ter em mente que há muita disputa entre os estudiosos do pensamento de Heidegger, e a tradução dos termos-chave de seu pensamento é um desses espaços de conflito em que, ao que tudo indica, não se chegou ainda a consenso. $O$ fato é que traduzir é ir em direção ao pensamento do termo-chave, embora sempre se necessite de comentários complementares à tradução. E ainda quando se opta por manter o termo em alemão, sempre há um comentário acompanhando a primeira ocorrência no texto.

Desse modo, a intraduzibilidade se evidencia em qualquer das situações, ao se traduzir os termos-chaves ou não, ao mesmo tempo que é extremamente relevante compreendê-los para liberar o pensamento em sua estada na fala heideggeriana. Como aponta a tradutora de Ser $e$ tempo, Marcia Sá Cavalcante Schuback, traduzir só é possivel enquanto um conduzir-se para aquilo a partir de onde fala a palavra. Traduzir não é simplesmente conduzir uma língua para outra, uma palavra para outra, mas conduzir a língua para o horizonte de experiência a partir do qual uma palavra se pronuncia, se enuncia ${ }^{22}$. Para Schuback, a não-tradução faz da palavra mais cotidiana em alemão, Dasein, a palavra mais esdrúxula quando pronunciada em português, "Dasein", tornando-se assim infiel à característica mais própria da linguagem de Heidegger ${ }^{23}$.

A respeito da segunda afirmação, os filósofos têm ótimas razões para colocar o humano no centro de suas investigações. No entanto, seria um equívoco pensar que o Dasein heideggeriano responde a essa mesma iniciativa. Nesse sentido, Casanova chama atenção para algo importante:

O termo "ser-ai" designa em um primeiro momento simplesmente o ser do homem. No entanto, ele não se mostra apenas como mais uma definição que irá incontornavelmente se juntar ao longo rol das definições cunhadas no interior da história do pensamento ocidental. Quase como se pudéssemos dizer: ser-aí é o conceito heideggeriano de homem. Não, não e uma vez mais não! O emprego do termo ser-aí indica no presente contexto uma transformação radical no modo mesmo de pensar o ser do homem. Antes de mais nada, é preciso ter em vista o fato de ser-aí não ser um termo cunhado por Heidegger a partir da pergunta: o que é o homem? O termo ser-aí inviabiliza desde o princípio a colocação de uma tal pergunta, na 
medida em que possui um modo de ser que o distingue fundamentalmente de todos os entes marcados pela presença de propriedades quididativas ${ }^{24}$.

Quanto ao terceiro apontamento, Heidegger esclarece sobre a necessidade de analisar o Dasein como horizonte para refletir sobre o sentido do ser: O que se busca é responder a questão do sentido do ser em geral e, antes disso, a possibilidade de elaborar radicalmente essa questão fundamental de toda ontologia. Liberar o horizonte em que o ser em geral é, de início, compreensível equivale, no entanto, a esclarecer a possibilidade da compreensão do ser em geral, pertencente à constituição desse ente que chamamos de presença ${ }^{25}$.

Afinal, o ser dos seres humanos é radicalmente diferente do ser dos demais entes no mundo. Para Heidegger, o Dasein é, necessariamente, aquele ente que carrega consigo a questão do sentido do ser: Esse ente que somos cada vez nós mesmos e que tem, entre outras possibilidades-de-ser, a possibilidade-de-ser do perguntar, nós o apreendemos terminologicamente como Dasein ${ }^{26}$. E é justamente nesse ponto de sua obra que Heidegger ${ }^{21}$ entende a analítica existencial do Dasein como caminho para pensar uma ontologia fundamental, ou seja, as condições de possibilidade da questão do sentido de ser.

No entanto, como indica Casanova, ontologia fundamental não significa aqui superontologia, mas aponta muito mais para a compreensão da necessidade de se perguntar antes de mais nada pela possibilidade mesma da ontologia ${ }^{27}$. A possibilidade de uma ontologia fundamental é, portanto, necessariamente articulada com a analítica existencial do Dasein, que por sua vez se vê agora no centro da meditação heideggeriana. Esses apontamentos, embora de natureza preambular, dado o espaço enxuto de um artigo, já nos confortam com novas perspectivas sobre a possibilidade de apreender o "ser humano" enquanto Dasein no campo da bioética.

É muito difícil acessar uma concepção definitiva de Dasein. Segundo o próprio Heidegger, o ser-aí permanece incomparável, não admite nenhum aspecto sob o qual pudesse ser subsumido como algo conhecido. (...) O ser-aí interrompe toda tentativa de explicação ${ }^{28}$. No entanto, a partir de uma perspectiva panorâmica capaz de esclarecer, ainda que provisoriamente, o Dasein heideggeriano, é possível compreender a virada paradigmática aqui proposta, sobretudo na dimensão da ação, da práxis. Este é, sem dúvida, o grande desdobramento dessa "nova" perspectiva de homem: o próprio sentido atribuído ao que significa "agir", no horizonte da bioética, é oriundo de uma empobrecida perspectiva do conceito de humano.

Como alerta Heidegger, o sentido dado à ação assenta-se em última instância sobre a interpretação do que é pensar ${ }^{29}$. Mas onde a ação é concebida como produção de um efeito, esta relação não é mais visível, e nenhuma "filosofia da ação" pode retornar ao ponto decisivo. Só o trabalho de "destruição" (Destruktion) do modo de pensar metafísico permite liberar a via de uma outra compreensão de humano e, portanto, do agir. Quanto mais conseguirmos avançar nesta via, mais pensar e agir não cessam de remeter um ao outro:

De há muito que ainda não se pensa, com bastante decisão, a essência do agir. Só se conhece o agir como a produção de um efeito, cuja efetividade se avalia por sua utilidade. A essência do agir, no entanto, está em con-sumar. Con-sumar quer dizer: conduzir uma coisa ao sumo, à plenitude de sua essência. Levá-la a essa plenitude, producere. (...) Por isso, em sentido próprio, só pode ser con-sumado o que já é. Ora, o que é, antes de tudo, é o Ser. O pensamento con-suma a referência do ser à essência do homem. Não a produz nem a efetua. $O$ pensamento apenas a restitui ao ser, como algo que lhe foi entregue pelo próprio $\mathrm{Ser}^{30}$.

Talvez a grande "virada" do conceito heideggeriano do Dasein consista na dissolução do modelo dual, sujeito-objeto, em que pensar e agir se encontram em comunhão fantasiosa. O Dasein está, desde sempre, querendo ou não, sabendo ou não, em determinado contexto significativo. Isto é, está sempre no desvelamento (aletheia), no aparecer, no mostrar-se das coisas, agindo e reagindo conforme determinado modo de desvelar que se apresenta no interior de cada situação.

Fogel diz bem quando explana: não que o real seja algo subexistente, apático, indiferente, ao qual se acople, se cole, se amolde algum sentido, alguma interpretação. (...) tudo que é e há, só é e há, porque já é sempre só e tão só sentido exposto, concretizado, realizado. Neste sentido, o homem não é autor desta interpretação, mas ele também obra, resultado, consequência. Não há quem ${ }^{31}$. O Dasein, irremediavelmente arremessado (Geworfen) no a-gente (das Man), encontra-se sempre imerso no falatório (Gerede).

Aqui, dois conceitos importantes foram citados pela primeira vez, e é necessário esclarecê-los. 0 primeiro deles, "a-gente", era utilizado por Heidegger para se referir a algo que está presente em todos nós. O a-gente retira o peso e a experiência da 
angústia (Angst) do Dasein, possibilitando reconfigurar a condição original e autêntica do humano como ser-no-mundo. O conceito pode ser compreendido a partir de certa visão de senso comum, opinião pública, ou a própria doxa grega. O Dasein tende a interpretar a si próprio enquanto "coisa", substância (Vorhandenheit), não compreendendo o óbvio sobre sua natureza enquanto ser-no-mundo, em contraste com as demais entidades de que se ocupa. Para Sloterdijk, nem mesmo a língua do a-gente diz alguma coisa própria, só participando do falatório ${ }^{32}$.

O falatório é, portanto, a redução das possibilidades do discurso (Rede) à tagarelice, ao falar indolente, à fofoca, ao papo furado, ao bate-papo. O falatório é a fala desarraigada da situação particular e da experiência de Dasein particular, transmitindo a interpretação geral, do impessoal, do a-gente. E, aqui, deve-se recorrer ainda a outro conceito: a curiosidade (Neugier), caracterizada pela constante necessidade de novidade, do que é sempre novo. $O$ curioso tagarela está sempre em busca de novidades.

Falatório e curiosidade dão origem à ambiguidade e à duplicidade. Quando se fala sobre tudo, apresentam-se como resolvidas questões cuja natureza deveria ser de constante abertura, aporia. Nesse ruído constante, em que desde sempre nos encontramos arremessados (Geworfen), há uma tendência de submissão ao a-gente, ao "eles", ao que eles dizem e fazem, e a esse processo Heidegger dá o nome de "queda" (Verfallen). A própria relação com outras entidades cujo modo de ser é como o do Dasein permanece contaminada pelo a-gente. Para Heidegger, a convivência no a-gente não é indiferente, mas sim tensa, pois trata-se de um escutar uns aos outros secretamente. Sob a máscara do ser um para o outro atua o ser um contra o outro ${ }^{33}$.

A própria redução do humano a sujeito, como procuramos investigar neste trabalho, é um dos produtos da "queda" do Dasein no falatório do a-gente. Aquilo que é demasiado próximo para ser evidente, a própria interpretação do nosso modo de ser como existência (ek-sistência) na abertura do aí, é prontamente encoberto pelo ruído do falatório, que potencializa uma fuga constante para o âmbito impessoal, do "eles", do "nós", do "a-gente". Segundo Schuback, Heidegger usou "existência" para designar toda a riqueza das relações recíprocas entre o Dasein, o ser, e todas as entificações, através desta entificação privilegiada: o homem. Nessa acepção, só o homem existe. A pedra é mas não existe. $O$ carro é mas não existe. Deus é mas não existe ${ }^{34}$.

Perdido nessa confusão, da qual ele próprio também é parte, o Dasein se torna surdo à sua voz interior, ao apelo de "algo" que o convida a tornar-se si mesmo, reunindo todas as suas possibilidades. Uma nota importante sobre esse aspecto encontra-se em Hervé Pasqua: Os outros [a-gente], não quer dizer: 0 resto dos homens para além de mim, dos quais o eu se dissociaria. Os outros são antes aqueles de que, o mais frequentemente, não nos distinguimos nós mesmos, entre os quais também nos encontramos ${ }^{35}$.

Ainda segundo Pasqua, perdendo-se na publicidade do Nós e do seu falatório, ele [o eu] faz, à força de escutar o Nós, orelhas moucas ao si mesmo próprio. Se o Dasein deve poder ser reconduzido, retirado desta perda onde não se escuta mais a si mesmo... é-lhe ainda necessário poder encontrar-se primeiro a si próprio, ao qual fez e continua a fazer orelhas moucas, não tendo ouvidos senão para o Nós. Este falatório exterior, este alarido ensurdecedor das palavras dos faladores, este canto das sereias que exerce a sua sedução na vida quotidiana, numa palavra a tirania do Nós, é dilacerada pelo apelo silencioso da consciência que reconduz o Dasein a si próprio: "Aquilo que, apelando, dá assim a compreender, é a consciência" ${ }^{36}$.

$\mathrm{O}$ apelo (Ruf) é, assim, grito silencioso que ressoa no interior do aí, como eco vindo de longe. Mas como se colocar à escuta deste apelo? Como "silenciar" o falatório no interior do aí e permitir-se ouvir o apelo que vem do longínquo para o longínquo? A filosofia é este dar-se conta disso, diz Fogel, o entrar nisso ${ }^{37}$ - apropriação tão necessária quanto distante no campo da bioética.

\section{Considerações finais}

Este trabalho procurou delinear, ainda que de maneira sucinta, os contornos de uma nova interpretação do humano. Por meio de breves apontamentos sobre a pobreza da ideia de humano enquanto sujeito, procuramos esboçar elementos para uma apropriação do conceito de Dasein. Entendemos que essa perspectiva, desde Heidegger, pode contribuir para mudar paradigmas ou - para nos mantermos no léxico heideggeriano - para um "outro início" (anderen Anfang) de conceitos importantes do campo da bioética.

Esse campo encontra-se há muito em horizontes de problematização sedimentados por determinada interpretação de ente. Nesse sentido, a virada paradigmática que ora propomos pretende enfrentar o soterramento dessas significações originárias, permitindo uma releitura profunda de conceitos como justiça, autonomia e tomada de decisão, todas herdeiras da metafísica da modernidade e desfiguradas de suas possibilidades profundas. Por isso não nos afastamos do 
sentido originário de ética, mas buscamos, de maneira sempre nova, produzir pequenas modulações dos pressupostos que se sedimentaram ao longo da tradição.

Nesse sentido, qualquer redução do "ser" humano ao meramente corporal ou mental, ou mesmo a um somatório dos dois, é fruto de um equívoco, um perder-se, um fundir-se no a-gente. Embora a existência do Dasein não seja solitária, sendo até mesmo impossível ser um absoluto si mesmo, independente dos outros, é preciso distinguir-se dos outros, subtrair-se do domínio alheio. Afinal, possuído pelo a-gente, já não é possível reconhecer-se, e desaparecemos no "nós". Interpretar-se enquanto sujeito é ceder ao convite tirânico do a-gente, é desaparecer no ruído do nós.

\section{Referências}

1. Heidegger M. Caminhos de floresta. Lisboa: Fundação Calouste Gulbenkian; 2002. p. 97.

2. McNeill W. The time of life: Heidegger and ethos. New York: Suny; 2006. p. 11. Tradução livre.

3. Haar M. Heidegger and the essence of man. Albany: State University of New York Press; 1993. p. 86. Tradução livre.

4. Heidegger M. Op. cit.

5. Haar M. Op. cit. p. 87. Tradução livre.

6. Heidegger M. Nietzsche. Rio de Janeiro: Forense; 2007. v. 2. p. 126.

7. Nietzsche F. A gaia ciência. Lisboa: Guimarães; 2000.

8. Nietzsche F. Assim falou Zaratustra. Rio de Janeiro: Nova Cultural; 2005.

9. Nietzsche F. Op. cit. 2000. p. 239.

10. Cabral AM. Heidegger e a destruição da ética. Rio de Janeiro: Editora UFRJ; 2009. p. 18.

11. Cabral AM. Op. cit. p. 19.

12. Heidegger M. Op. cit. 2007.

13. Heidegger M. Op. cit. 2007. p. 127.

14. Heidegger M. Serenidade. Lisboa: Instituto Piaget; 2001.

15. Castro JC. A humanidade esquecida: a ciência na esteira da "metafísica da modernidade". Princípios [Internet]. 2016 [acesso 30 out 2020];23(42):125-50. p. 138. DOI: 10.21680/1983-2109.2016v23n42ID9046

16. Heidegger M. Heráclito. Rio de Janeiro: Relume Dumará; 1998. p. 102.

17. Fogel G. Homem, realidade, interpretação. Rio de Janeiro: Mauad X; 2015. p. 13.

18. Fogel G. Op. cit. p. 16.

19. Kierkegaard S. The concept of anxiety. Princeton: Princeton University Press; 1980. p. 42.

20. Fogel G. Op. cit. p. 17.

21. Heidegger M. Ser e tempo. Petrópolis: Vozes; 2006.

22. Schuback MSC. A perplexidade da presença. In: Heidegger M. Op. cit. 2006. p. 15-32. p. 17.

23. Schuback MSC. Op. cit. p. 18.

24. Casanova MA. Compreender Heidegger. Petrópolis: Vozes; 2009. p. 89.

25. Heidegger M. Op. cit. 2006. p. 303-4.

26. Heidegger M. Op. cit. 2006. p. 42.

27. Casanova MA. Op. cit. p. 79.

28. Heidegger M. Mindfulness. Norfolk: Continuum International Publishing Group; 2006. p. 288. Tradução livre.

29. Heidegger M. Sobre o humanismo. Rio de Janeiro: Tempo Brasileiro; 1995. p. 24.

30. Heidegger M. Op. cit. 1995. p. 23-4.

31. Fogel G. Op. cit. p. 54.

32. Sloterdijk P. Critique of cynical reason. Minneapolis: University of Minnesota Press; 2001. p. 197. Tradução livre.

33. Heidegger M. Ser e tempo. Op. cit. 2006. p. 239.

34. Schuback MSC. Notas explicativas. In: Heidegger M. Ser e tempo. Op. cit. 2006. p. 561-82. p. 562.

35. Pasqua H. Introdução à leitura do Ser e Tempo de Martin Heidegger. Lisboa: Instituto Piaget; 1993. p. 67.

36. Pasqua H. Op. cit. p. 135.

37. Fogel G. Op. cit. p. 57.

\section{Participação dos autores}

Ambos os autores colaboraram na revisão bibliográfica. João Cardoso de Castro redigiu o manuscrito. Murilo Cardoso de Castro realizou a revisão crítica do manuscrito.

\section{Correspondência}

João Cardoso de Castro - Centro Universitário Serra dos Órgãos. Av. Alberto Torres, 111, Alto CEP 25964-004. Teresópolis/RJ, Brasil.

João Cardoso de Castro - Doutor - joaocardosodecastro@gmail.com

(D) $0000-0002-3811-405 \mathrm{X}$

Murilo Cardoso de Castro - Doutor - murilocdecastro@gmail.com

(iD) $0000-0001-8809-5443$ 